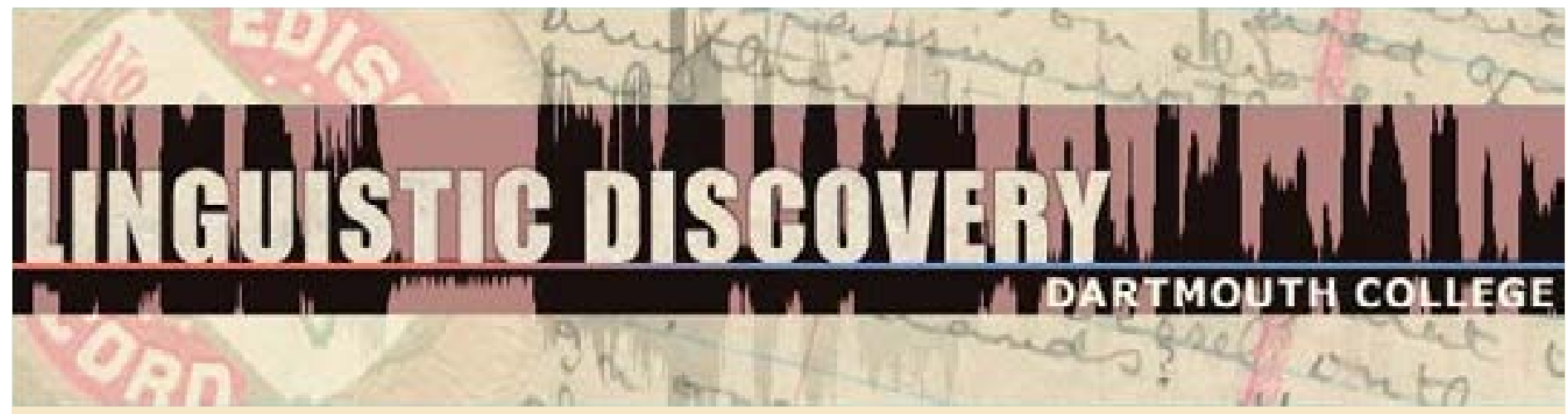

Volume 10

Issue 1 2012
Variation in Clause Combining: Views from the New World

Jeanette Sakel, Marianne Mithun and Pier Marco Bertinetto

doi: 10.1349/PS1.1537-0852.A.402

url: http://journals.dartmouth.edu/cgi-bin/WebObjects/ Journals.woa/1/xmlpage/1/article/402 


\title{
Variation in Clause Combining: Views from the New World
}

\author{
Jeanette Sakel, Marianne Mithun and Pier Marco Bertinetto
}

\section{Introduction}

It has long been recognized that the density of syntactic complexity is greater in written varieties of certain languages than in their spoken counterparts (Chafe 1985, Romaine 1992, Newmeyer 2002, Karlsson 2007, Mithun 2009, Laury and Ono 2010, and others). Such differences are not surprising: writers have the luxury of time to construct elaborate complex sentences, and readers the leisure to unpack them, while speakers and listeners must perform on the fly. Furthermore, writers must communicate without the benefit of prosody, a key dimension of speech, which can indicate much about the relationships between propositions. Writers are obligated to specify such relationships by other means, typically complex syntactic constructions. Some languages with uniquely oral traditions have been argued to lack syntactic complexity altogether, as seen in the recent flurry of discussion about Pirahã (Everett 2005, 2009, Nevins, Pesetsky, and Rogrigues 2009a,b, Sakel and Stapert 2010). Many languages without longstanding written traditions have recently borrowed conjunctions, complementizers, and relativizers from the European languages of colonizers, languages with deeply entrenched literary practices. Spanish loans of this type, for example, are particularly prominent in indigenous languages of Mesoamerica and South America. We know that structures developed within literary genres can enter the speech of writers, perhaps first in more formal registers. From there they might be passed on to other languages without writing through bilinguals. The effects need not be restricted to lexical loans. As illustrated by Johanson (2002), Heine and Kuteva (2006), Matras and Sakel (2007) and others, contact can affect grammar through grammatical replication or copying of structures from one language to another, even with no transfer of substance. These observations raise questions about how and why languages might differ in their distribution of information over sentences, in particular, in the forms, functions, and density of dependent clause constructions.

In addition to the written/spoken channel, and exposure to languages with extensive literary traditions, certain typological features might correlate with differences in clause-combining strategies. There might, for example, be correlations between basic constituent order and the types of dependent clauses that develop and that can be processed easily enough by listeners to persevere. Certain patterns of syntactic complexity, such as clause chaining, might be handled more easily than others in spoken language. Many languages, particularly in the New World, can convey within a single word what can only be expressed in a multi-word sentence in most European languages. Does the difference in the distribution of information between morphology and syntax impact the distribution of information between simple and complex sentences? In a number of languages of the Americas (and beyond), formal dependency marking is used not only to mark syntactic dependency within the sentence, but also discourse dependency in larger stretches of speech (Mithun 2008). Such patterns raise interesting questions about the status of the sentence in languages without prescriptive norms for written texts.

The goal of this volume is to shed light on clause linkage patterns in a range of Amerindian languages, as well as on the typological co-variates of clause combining. The patterns under discussion include polysynthesis, complementation, relativisation, parataxis and switch reference. Most languages are without lengthy literary traditions and are in contact with "colonizer" languages, and many have quite different grammatical structures from European 
languages. However, the ways clauses are combined in these languages are quite distinct, and we find considerable variation in the functions and density of syntactic complexity.

This special issue arises from a workshop with the same title held at the SLE in Vilnius in 2010.

The individual papers consider various aspects of the following:

*The status of the sentence: How clear is the notion of the sentence in the language in question, and does it correlate tightly with that of better-known languages?

*Interclausal relations: Is there a strong contrast between clause coordination and subordination? Are intermediate structures detectable?

*Order: Are all alternative orders possible between main and subordinate clauses, and if so, does order have syntactic, semantic, or pragmatic consequences?

*Inventories of dependent clauses: What kinds of dependent clauses exist in the language? What are their forms and functions? Do their uses and densities correspond to those of better-known languages? If formally dependent clauses are rare or nonexistent, what alternatives are there for indicating relationships among propositions?

*Prosody: How do prosodic patterns correlate with grammatical patterns of clause combining?

*Genre: Do patterns and densities of clause combining differ across genres or registers within the language? Ritual language, for example, can resemble literary languages in the fact that it is not typically created on the fly, but is the result of generations of polishing, and is familiar to both the speaker and the listeners. Formal oratory and traditional legends often show similar characteristics. Do such genres differ significantly in their complexity of clause combining from more informal speech, particularly conversation?

*Contact: Can any effects be discerned of contact with a language that does have a literary tradition (Spanish, Portuguese, French, English)? Is it possible to correlate these effects with degrees of bilingualism in the communities?

*Translations: How do the density and functions of dependent clauses in translations of works from European languages, such as the Bible, correlate with those in native speech?

*The impact of writing: If the indigenous language is written, how does the density and nature of syntactic complexity differ in written language from that of spoken language? How old is the written tradition, and how widespread is it? What proportion of writers are bilingual in another language with a lengthy written tradition?

The seven articles in this volume are ordered according to the geographical locations of the languages discussed.

Starting in the north with Central Alaskan Yupik, Mithun discusses a scenario in which syntactic complexity has arisen in a language without a literary tradition and without the presence of language contact. While syntactic complexity is low in modern Yupik, she argues that Central Alaskan Yupik has complex morphological constructions, which have developed from complex syntactic constructions. These include affixes for matrix verbs such as 'think that' 'say that', 'believe that', which developed from phonologically reduced independent verbs. Additionally, the language makes use of morphological mood markers, which can express various types of conceptual embedding. Drawing on a wide range of diachronic and synchronic data, Mithun also includes evidence from the prosody of Yupik. 
Chafe's paper deals with one of the main markers at the basis of complex syntactic constructions in Seneca, a Northern Iroquoian language: the most common word in that language, the particle neh. Chafe describes this particle as an amplification marker, which indicates that more information about a pronominal referent is to follow. Neh can be used with nouns within the same prosodic phrase as the pronominal trigger, or it can stretch across prosodic phrases, appearing with nouns, nominalised verbs and fully fledged verbs. He argues that in the latter case, neh is used to link clauses and thereby contributes to the syntactic complexity of the language.

Bakker and Hekking discuss the status of syntactic complexity in the Mexican language Otomi from two perspectives. Firstly, they explore whether a corpus of this predominantly spoken language exhibits fewer syntactically complex structures than that of a language with a long literary tradition. They find that compared with Spanish, Otomi has far fewer markers for interclausal relations, and such markers are employed with less frequency. Secondly, they explore whether language contact with Spanish has led to changes in the syntactic complexity of Otomi. Their findings are that, indeed, the majority of markers indicating coordination and subordination are borrowed from Spanish, yet it is unlikely that these loans have replaced native markers. In the case of Otomi, contact with a language with a long written tradition has led to a considerable increase in the overt marking of coordination and subordination.

Faarlund's contribution deals with the Zoque language of southern Mexico. He argues that this language has considerable syntactic complexity. There are a wide variety of subordination constructions, including those featuring independent complementizers and $\mathrm{WH}$-elements, cliticized complementizers, relative clauses as well as structures characterized by the mere juxtaposition of the two linked clauses. Zoque has only recently been introduced to a written form, and according to Faarlund, neither writing nor language contact with Spanish can be made responsible for the degree of complexity in the language.

Moving on to South America, Sakel explores syntactic complexity in Portuguese learner varieties employed by Pirahã men. Their first language, Pirahã, is a language without syntactic complexity, as opposed to Portuguese, which is complex in e.g. overtly marking for subordination. Her results show that all but the more proficient Portuguese speakers use simple syntactic constructions in Portuguese, which is expected in early learner language, but which also resembles the structure of Pirahã. Yet, the two most proficient speakers use constructions that can be argued to be syntactically complex, indicating that syntactic complexity can be introduced even to speakers of a language that has very little complexity itself.

Bertinetto and Ciucci describe a para-hypotactic construction in the Zamucoan languages Ayoreo and Chamacoco. This construction is syntactically complex in containing a proleptic dependent clause, while the main clause is linked to the latter by a marker of coordination. Hitherto, para-hypotaxis has predominantly been described for Old Romance languages, but the authors argue that it is probably a much more widespread feature found in other languages of the world. It furthermore appears to be an areal phenomenon in the Chaco region, where the Zamucoan languages are spoken. The authors investigate this phenomenon in spoken and written corpora of the languages, addressing the question of differentiating levels of complexity in the two modes. They find that syntactic complexity is less apparent in the spoken language, especially when compared to highly formal written sources, such as bible translations.

The final paper of the volume by van Gijn gives an overview of switch attention systems in South American languages. Focusing on temporal clauses, he investigates how switch attention can aid textual cohesion in orally transmitted languages, including discourse coherence, 
information structure and preparation for things to come. The author argues that switch attention can furthermore contribute to a reduction in morphosyntactic complexity, for example by reducing person marking in continuity clauses, fusion with and reduction of other categories, such as the presence of a passive voice and gender systems. Due to the usefulness of this category in oral languages, the author argues that the phenomenon can easily diffuse in language contact situations, which would explain why it is widespread in South American languages.

\section{Contents}

Marianne Mithun 'Exuberant Complexity: The Interplay of Morphology, Syntax, and Prosody in Central Alaskan Yup'ik'

Wallace Chafe 'The Seneca amplification construction'

Dik Bakker \& Ewald Hekking 'Clause Combining in Otomi before and after contact with Spanish'

Jan Terje Faarlund 'Degrees of clause cohesion: complementation and subordination in Chiapas Zoque'

Jeanette Sakel 'Acquiring complexity: the Portuguese of some Pirahã men'

Pier Marco Bertinetto \& Luca Ciucci 'Parataxis, hypotaxis and para-hypotaxis in the Zamucoan languages'

Rik van Gijn 'Switch-attention (aka switch-reference) in South-American temporal clauses: facilitating oral transmission'

Editors' Contact Information:

Jeanette Sakel

Jeanette.Sakel@uwe.ac.uk

Marianne Mithun

mithun@linguistics.ucsb.edu

Pier Marco Bertinetto

pier.marco@bertinetto.eu 